Revue

Revue de l'histoire des religions

de Ihistoire des religions

\title{
Alexandre Faivre, Chrétiens et Églises : des identités en construction. Acteurs, structures, frontières du champ religieux chrétien
}

Paris, Cerf (« Histoire »), 2011

Alain Rauwel

\section{(2) OpenEdition}

\section{Journals}

Édition électronique

URL : http://journals.openedition.org/rhr/8209

DOI : $10.4000 /$ rhr.8209

ISSN : 2105-2573

Éditeur

Armand Colin

\section{Édition imprimée}

Date de publication : 1 mars 2014

Pagination : 130-132

ISBN : 978-2200929107

ISSN : 0035-1423

Référence électronique

Alain Rauwel, «Alexandre Faivre, Chrétiens et Églises : des identités en construction. Acteurs, structures, frontières du champ religieux chrétien ", Revue de l'histoire des religions [En ligne], 1 | 2014, mis en ligne le 13 mai 2014, consulté le 22 septembre 2020. URL : http://journals.openedition.org/rhr/8209 ; DOI: https://doi.org/10.4000/rhr.8209

Ce document a été généré automatiquement le 22 septembre 2020

Tous droits réservés 


\title{
Alexandre Faivre, Chrétiens et Églises : des identités en construction. Acteurs, structures, frontières du champ religieux chrétien
}

Paris, Cerf (« Histoire »), 2011

\author{
Alain Rauwel
}

\section{RÉFÉRENCE}

Alexandre Faivre, Chrétiens et Églises : des identités en construction. Acteurs, structures, frontières du champ religieux chrétien, Paris, Cerf (« Histoire »), 2011, 608 p., 23,5 cm, $43 €$, ISBN 978-2-204-09387-3.

1 Les livres dont on fait le plus grand bruit ne sont pas nécessairement, loin s'en faut, les plus décisifs ; inversement, des sommes élaborées dans la discrétion s'imposent au bout du compte comme des références majeures. Telle est l'œuvre d'Alexandre Faivre, mûrie au long de quatre décennies d'enseignement et de recherche à la Faculté de Théologie catholique de l'Université de Strasbourg: l'une des plus considérables de notre temps. Le recueil d'articles et de communications qui paraît aujourd'hui rassemble en une gerbe les fruits les plus significatifs de ce patient travail, révélé aux historiens par le maitre-livre que fut Ordonner la fraternité. On pourra critiquer, sans doute, les redites qui marquent cette publication : elles étaient inévitables, sauf à réécrire entièrement six cents pages bourrées de faits et d'arguments, ce qui eût été un travail de titan et, probablement, une perte pour le lecteur, qui aime à retrouver les circonstances fort diverses dans lesquelles les deux douzaines de contributions rassemblées ont été préparées.

2 La lente organisation des Églises chrétiennes est l'objet propre d'A. Faivre. Comment, d'une communauté de prière unie par la charité et l'attente eschatologique, est-on 
passé à un système hiérarchique élaboré et contraignant? Par quelles procédures de sélection et d'exclusion ceux qui, aux origines, réservaient le nom de prêtre (hiereus) au seul Christ sauveur ont-ils inventé cette structure si peu cohérente avec la prédication $\mathrm{du}$ fondateur: un clergé ? Comment, notamment - c'est un point qui intéresse vivement A. Faivre, qui écrit souvent en duo avec son épouse - les femmes ont-elles été radicalement mises à l'écart du dispositif? Autant de questions qui vont de soi pour l'historien, mais heurtent parfois de front un discours institutionnel prompt à affirmer que rien n'a jamais changé - semper idem... Les méthodes du chercheur sont sûres. Il accorde toute sa place à la lexicographie et suit avec une attention aiguë les tournants de l'histoire des mots essentiels : « chrétien », « clergé », « laïc »... On dispose pour ces deux derniers termes de la traduction, infiniment précieuse, des notices données par A. Faivre au Reallexikon für Antike und Christentum. L'auteur ne se prive pas non plus de reprendre méthodiquement les questions posées par les pièces les plus anciennes et les plus discutées des dossiers qu'il examine. "Clément de Rome » et « Ignace d'Antioche », c'est-à-dire ceux qui se cachent sous ces noms prestigieux, bénéficient d'un close reading générateur de riches analyses, de même que la documentation canonico-liturgique qui culmine dans la pseudo-Tradition apostolique.

3 Les remarques historiographiques d'A. Faivre sont ici d'une grande acribie. Il note que, nonobstant les appels systématiques à "l'origine», ce lieu mythique de toutes les puretés, ce n'est pas au $\mathrm{I}^{\mathrm{er}}$ siècle que les rénovateurs du catholicisme à la génération de Vatican II se sont attachés. La période de tous leurs enthousiasmes correspond à la fin $\mathrm{du} \mathrm{II}^{\mathrm{e}}$ et à la première moitié du III $^{\mathrm{e}}$ siècle (180-260), c'est-à-dire non à un moment d'ébullition mais à une phase de mise en ordre, de sacerdotalisation, pour ainsi dire de normalisation. Le supposé Hippolyte de Rome a servi de fixateur à ce qu'il faut bien appeler un fantasme, comme l'a montré aussi un autre Strasbourgeois, Marcel Metzger. De ce point de vue, il n'est pas très cohérent qu'A. Faivre tienne à célébrer malgré tout - question de génération, sans doute - les travaux d'un Bernard Botte, dont la recherche récente a manifesté l'inanité. Les textes liturgiques ne sont de toute façon pas justiciables d'une lecture monolithique, tant il est vrai qu'« un même rituel peut conserver des strates correspondant à des problématiques, des pratiques ou des souhaits provenant d'époques et de contextes très différents ».

Le problème posé dans tout le livre est celui des ministères. L'insistance initiale sur la diaconie (Paul lui-même se désigne comme diakonos en Col 1,25) évolue sous l'action du développement cérémoniel de la nouvelle religion : "absorption par le culte ", propose A. Faivre, ce qui vaut mieux à coup sûr que la discutable « aliénation par le culte » de Cyrille Vogel. Un modèle sacerdotal inspiré des prescriptions lévitiques se met en place, qui appelle par sa technicité nouvelle une professionnalisation (Georg Schöllgen) et la structuration d'un groupe peu à peu hiérarchisé, comme l'était l'administration impériale, au moyen du cursus. Cyprien peut alors voir dans le sacerdoce, non seulement un service, mais un honneur. Et le "prince» du collège sacerdotal est l'évêque, au terme d'une évolution sémantique qui a fait descendre sur terre l'episcopos véritable des premières générations, qui était Dieu seul. Les études soulignent avec pertinence les conséquences matérielles de ce bouleversement des équilibres communautaires: outre que la manipulation des sancta impose la continence aux professionnels du culte, il leur faut une rémunération, et « les clercs sont désormais les assistés matériels des laïcs qu'ils assistent spirituellement ». Car il y a maintenant des 
« laïcs », alors que rien n'est moins primitif que cette notion; ils sont aux membres de la hiérarchie ce que les enfants sont aux adultes...

5 Tout cela ne s'est pas fait sans tensions, comme le montre la lettre de "Clément » aux Corinthiens, dont l'importance, soulignée en son temps par Rudolf Sohm, est proportionnelle à la virulence des débats qu'elle a suscités. Le statut des diacres est un bon exemple de ces tensions : obstinément ramenés à un prestige inférieur à celui des presbytres, ils ont en même temps, ne serait-ce que par le malthusianisme de leur corps, conservé un pouvoir qui suscitait les envies. A. Faivre a certainement raison, ici, de suggérer que bien des affrontements rangés par la tradition sous l'étiquette commode d'« hérésies » furent en fait des luttes d'influences bien plus que des conflits doctrinaux abstraits. Tertullien, dont l'auteur a rappelé avec persévérance le rôle capital dans les débats ecclésiologiques, est-il un déviant, ou seulement un empêcheur d'épiscopaliser en rond, un défenseur de la dignité sacerdotale du peuple chrétien ?

On le voit, c'est à un considérable dépoussiérage de l'histoire institutionnelle du premier christianisme qu'invitent les recherches d'A.Faivre. En soulignant les évolutions des trois premiers siècles, en mettant en lumière les principes d'innovation à l'œuvre quasiment à chaque génération, il aura rendu un service signalé non seulement aux historiens de l'antiquité, mais à tous ceux qui, confrontés aux relectures et aux instrumentalisations des Pères lors des phases successives du développement dogmatique et canonique, ont à cœur de savoir ce qu'il en fut vraiment de ces siècles où la légende dorée ne voudrait voir que cor unum et anima una.

\section{AUTEURS}

\section{ALAIN RAUWEL}

Université de Bourgogne, Dijon 